\title{
ASSESSMENT OF POTENTIAL HEALTH HAZARDS DURING EMISSION OF HYDROGEN SULPHIDE FROM THE MINE EXPLOITING COPPER ORE DEPOSIT - CASE STUDY
}

\author{
Małgorzata Kupczewska-Dobecka, Sławomir Czerczak, Jan P. Gromiec, Katarzyna Konieczko \\ Department of Chemical Safety, Nofer Institute of Occupational Medicine, Lodz, Poland
}

\begin{abstract}
SUMMARY
Aim: The aim of this study was to determine hydrogen sulphide concentration emitted from the mine extracting copper ore, to evaluate potential adverse health effects to the population living in four selected villages surrounding the exhaust shaft.

Materials: Maximum measured concentration of hydrogen sulphide in the emitter is $286 \mu \mathrm{g} / \mathrm{m}^{3}$. Maximum emission calculated from the results of determinations of concentrations in the emitter is $0.44 \mathrm{~kg} / \mathrm{h}$.

Results: In selected villages hydrogen sulphide at concentrations exceeding $4 \mu \mathrm{g} / \mathrm{m}^{3}$ was not detected in any of the 5 -hour air samples. In all locations, the estimated maximum 1-hour concentrations of hydrogen sulphide were below $1 \mu \mathrm{g} / \mathrm{m}^{3}$, and the estimated mean annual concentrations were below $0.53 \mu \mathrm{g} / \mathrm{m}^{3}$.

Conclusion: Any risk to the health of people in the selected area is not expected. As indicated by the available data on the threshold odour, the estimated concentrations of hydrogen sulphide may be sensed by humans.
\end{abstract}

Key words: hydrogen sulphide determination, copper ore mine, model estimation, odour

Address for correspondence: M. Kupczewska-Dobecka, Nofer Institute of Occupational Medicine, Department of Chemical Safety, St. Teresy Str. 8, 91-348 Lodz, Poland. E-mail: dobecka@imp.lodz.pl

\section{INTRODUCTION}

Copper deposit in south-western Poland (Legnica-Glogow District), originate from sediments of the Permian period. The series of ore in the form of dark deposits rich in organic matter and containing metal sulphides, or as deposits with red spots devoid of organic matter are carriers of iron oxide. Room pillar technology is used to extract copper ore in the underground part of the mine. The room pillar technology involves breaking the ore using explosives, taking the winning from the mine face, bringing it by diesel-powered machines to the loading spots, placing it on conveyor belts to convey it to the region of the output shaft, pre-crushing of the copper ore and bringing it through the output shaft to the surface. In the mine headings where the ceiling layers are located close to the anhydrite rock, leakage of subsurface natural gas has been occasionally recorded. Pollutants lifted into the mine ambient air during the mining operations are discharged with the air into the atmosphere. Mine headings are ventilated using the ventilation system consisting of air supply shaft that supplies fresh atmospheric air to the underground headings and exhaust shafts discharging the polluted air from the headings to the outer atmosphere.

Emissions of gases and vapours, which can cause unpleasant sensations of smell is an important issue for people living close to the exhaust shafts. Air pollution is the reason for subjective reactions of the inhabitants which are reflected in the complaints addressed to different offices managing the environment. Ac- cording to the data obtained from the Ministry of Environment in 2013, as much as 1,323 air pollution complaints were recorded in Poland; of those, 869 (over 65.7\%) referred to odour. Unfortunately, inhabitants cannot start effective action, because current regulations do not contain instruments that would make possible to assess if odour intensity is below or above the permissible limits. It is expected that the problem will increase. At the end of January 2014, the Ministry of the Environment granted a license for further exploration and prospecting of copper ore deposits.

In the USA, investigators have recently found connection between coal production and adverse health effects, including increased risk of respiratory diseases among residents of the area affected by emissions (1). Sulphide is liberated as a gas, creating conditions in coalfield homes where short-term and long-term exposures can exceed applicable health standards.

The aim of this study was to determine hydrogen sulphide concentration emitted from the mine extracting copper ore to evaluate hazard and annoyance associated with emission and immission of this chemical as well as to assess the risk of potential adverse health effects to the population living in the area surrounding the exhaust shaft.

\section{MATERIALS AND METHODS}

The subject of the study is an underground mine operating copper ore deposit within the mining areas on the border of the 
municipalities Radwanice and Jerzmanowa in the area of Sieroszowice. The population of the Jerzmanowa municipality is approximately 4,000 and the area is $63.5 \mathrm{~km}^{2}$. The southern border of the square shaft is adjacent to a large forest complex and the remaining sides of the square shaft are surrounded by agricultural land - mostly arable. On the northern and north-eastern side of the shaft area approximately $1 \mathrm{~km}$ from the nearest emitters, there are areas of the densely inhabited villages of Jakubow and Maniow. At a distance of about $1.6 \mathrm{~km}$ north-west from the nearest emitters runs the southern border of the forest nature reserve Buczyna Jakubowska.

The tests were carried out in the shaft used to remove the stale air from the mine headings, equipped with a ground station provided with 4 axial fans. The nominal capacity of each fan is $400 \mathrm{~m}^{3} / \mathrm{s}$. The fans were connected to individual diffusers with outlets at the height of $36.3 \mathrm{~m}$, the surface area of the outlet crosssection being $\mathrm{S}=46.6 \mathrm{~m}^{2}$. During normal use, 3 fans are operative, and the fourth serves as a reserve. The purpose of ventilation is to remove air polluted during mining work as a result of diesel fuel combustion, detonation of explosives, handling and transport of the winnings, and maintenance works.

For quantitative determination of hydrogen sulphide in the exhaust diffuser, a method was used in which hydrogen sulphide absorbed in the solution of zinc acetate reacted with N,N-dimethyl-p-phenyldiamine in the presence of iron (III) chloride to form methylene blue serving as the basis for spectrophotometric determination. The method characterized by the lower limit of quantitation (LOQ) of $0.05 \mu \mathrm{g} / \mathrm{ml}$ of the solution of absorbent and allowing collection of up to 600 litres of air was used $(2,3)$. Air samples for the determination of hydrogen sulphide were collected from the diffuser to the scrubber absorbent solution (acidic solution of zinc acetate) protected from light with aluminium foil. A total of 20 samples were collected at two levels of the diffuser. Samples were collected at a constant volume flow rate (VFR) of 20 l/h, for 30 minutes. Additional 5 samples were collected by insulation methods into 10 liters Tedlar ${ }^{\circledR}$ bags covered with aluminum, head-space vials. The air from the bag then passed through a scrubber absorbent solution and assayed for the concentration of hydrogen sulfide as in the case of earlier samples.

Immission measurement sites were selected within walking distance from the emitter as a result of reconnaissance - the intensity of the characteristic odour of sulphur compounds served as the criterion for selection of the sampling site. Unpleasant sensations of smell for people living close to the exhaust shafts were found in these villages: $2.06 \mathrm{~km}$ E (Jerzmanowa), $3.35 \mathrm{~km}$ NW (Bukwica), $3.3 \mathrm{~km} \mathrm{SW}$ (Przesieczna), and about $5 \mathrm{~km} \mathrm{NE}$ (Jaczow). The tests were carried out in summer. At selected sites, 24 air samples were collected for the determination of hydrogen sulphide. In each of the measuring points five samples of air were collected successively with a volume of 601 with a constant VFR $60 \mathrm{l} / \mathrm{h}$ and simultaneously one 5-hours sample with a volume of 300 liters was collected. Based on LOQ corresponding maximum hydrogen sulphide concentrations in the air were equal to $20 \mu \mathrm{g} /$ $\mathrm{m}^{3}$ and $4 \mu \mathrm{g} / \mathrm{m}^{3}$, respectively. The methodology described above was used for collecting the samples of the air in selected locations.

The calculations of the distribution of hydrogen sulphide released from the shaft into the ambient air were performed using the Gaussian Dispersion Modelling - ZANAT ${ }^{\circledR}$ software package compatible with the ordinance by the Minister of Environment of
26 January 2010 on the Reference values for certain substances in the air (4). The software enables calculations of atmospheric air pollution resulting from the activities of the arrays of the point, the linear and the surface emission sources.

Maximal concentration $\mathrm{S}_{\mathrm{m}}\left(\mu \mathrm{g} / \mathrm{m}^{3}\right)$ of a gaseous substance averaged over one hour in specified atmospheric conditions is calculated from the formula:

$$
S_{\mathrm{m}}=\mathrm{C}_{1} \frac{\mathrm{E}_{\mathrm{g}}}{\mathrm{uAB}}\left(\frac{\mathrm{B}}{\mathrm{H}}\right)^{\mathrm{g}} \times 1000
$$

Where:

$\mathrm{E}_{\mathrm{g}}$ - maximum emission

$\mathrm{C}_{1}$ - tabularized constants dependent on atmospheric equilibrium

A - indicator of atmospheric horizontal diffusion

$\mathrm{B}$ - indicator of atmospheric vertical diffusion

$\mathrm{u}-$ wind speed

$\mathrm{H}$ - effective height of the emitter

Maximum emission $\left(\mathrm{E}_{\mathrm{g}}\right)$ was calculated from the results of determinations of concentrations in the emitter. Indicators of horizontal and vertical diffusion (A, B) are calculated by ZANAT ${ }^{\circledR}$ in each of mesh node, depending on parameters such as effective height of the emitter, average aerodynamic roughness of the area around the emitter and coefficients of state of equilibrium atmosphere. Effective height of the emitter $(\mathrm{H})$ depends on geometric height and diameter of emitter, offgas velocity and temperature. Meteorological data (windrose) necessary for the calculations were obtained from the Institute of Meteorology and Water Economy. In immission modelling, the following parameters based on information received from the contractor were assumed: emitter equivalent diameter $9.97 \mathrm{~m}$, offgas velocity $5.49 \mathrm{~m} / \mathrm{s}$, offgas temperature $293^{\circ} \mathrm{K}$, average aerodynamic roughness of the area around the emitter 1.09. For the purpose of the calculations the area of $10 \times 10 \mathrm{~km}$ was applied, which included the villages selected for the analysis. Background level for $\mathrm{H}_{2} \mathrm{~S}$ was set at $10 \%$ of the reference values averaged over one year. In Poland, the reference values for hydrogen sulphide that are unlikely to cause adverse health effects in the general population are $5 \mu \mathrm{g} /$ $\mathrm{m}^{3}$ (averaged over the period of the year) and $20 \mu \mathrm{g} / \mathrm{m}^{3}$ (averaged over one hour).

\section{RESULTS}

Maximum measured concentration of hydrogen sulphide in the emitter was $286 \mu \mathrm{g} / \mathrm{m}^{3}$. Maximum emission $(0.44 \mathrm{~kg} / \mathrm{h})$ was calculated from the results of determinations of concentrations in the emitter taking into account gas volume flow in the emitter equals $20 \mathrm{l} / \mathrm{h}$.

At selected sites of Jerzmanowa, Bukwica, Przesieczna, and Jaczow, on measurement days in any of the 1-hour air samples, hydrogen sulphide was not detected at concentrations exceeding $20 \mu \mathrm{g} / \mathrm{m}^{3}$ and simultaneously in any of the 5-hour air samples, hydrogen sulphide was not detected at concentrations exceeding $4 \mu \mathrm{g} / \mathrm{m}^{3}$.

The largest model-estimated maximum concentration of hydrogen sulphide averaged over one hour (taking into account the assumed background level of $0.5 \mu \mathrm{g} / \mathrm{m}^{3}$ ) was $1.91 \mu \mathrm{g} / \mathrm{m}^{3}$, corresponding to less than $10 \%$ of the reference value, and it was found in three points, within about $141 \mathrm{~m}$ south-east, north-east 
and north-west of the emitter. Concentrations above $1.5 \mu \mathrm{g} / \mathrm{m}^{3}$ occur only within a radius of less than $400 \mathrm{~m}$ from the emitter. The north-eastern part of the area is the area of the plant.

In all selected villages, the estimated maximum 1-hour concentration of hydrogen sulphide was below $1 \mu \mathrm{g} / \mathrm{m}^{3}$, the lowest in Jaczow, below $0.8 \mu \mathrm{g} / \mathrm{m}^{3}$ (Fig. 1).

Distribution of mean annual concentrations of hydrogen sulphide in the immediate vicinity of the emitter shows that the highest estimated mean annual concentration of hydrogen sulphide was $0.628 \mu \mathrm{g} / \mathrm{m}^{3}$ (including the background), and was located approximately $300 \mathrm{~m}$ to the east from the emitter. Concentrations above $0.55 \mu \mathrm{g} / \mathrm{m}^{3}$ only occur in an area eastward from the emitter at a distance of less than $900 \mathrm{~m}$ (Fig. 2).

Model-estimated mean annual hydrogen sulphide concentrations in all selected villages were below $0.53 \mu \mathrm{g} / \mathrm{m}^{3}$ including background.

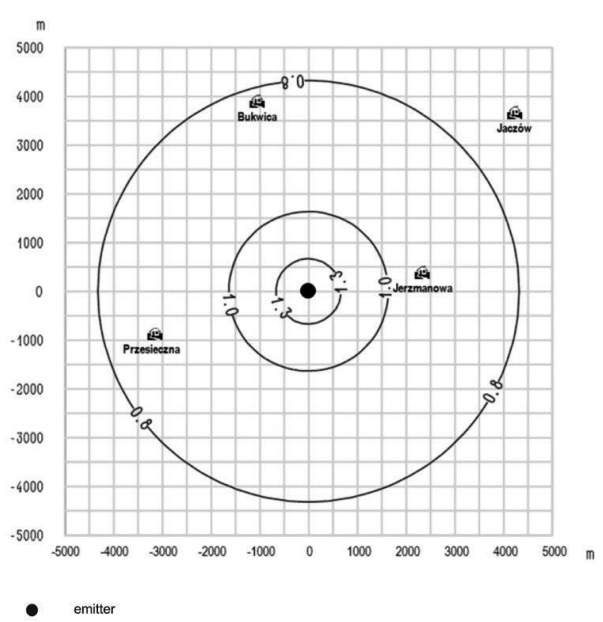

Fig. 1. Model - estimated maximum 1-hour concentration of hydrogen sulphide in selected village.

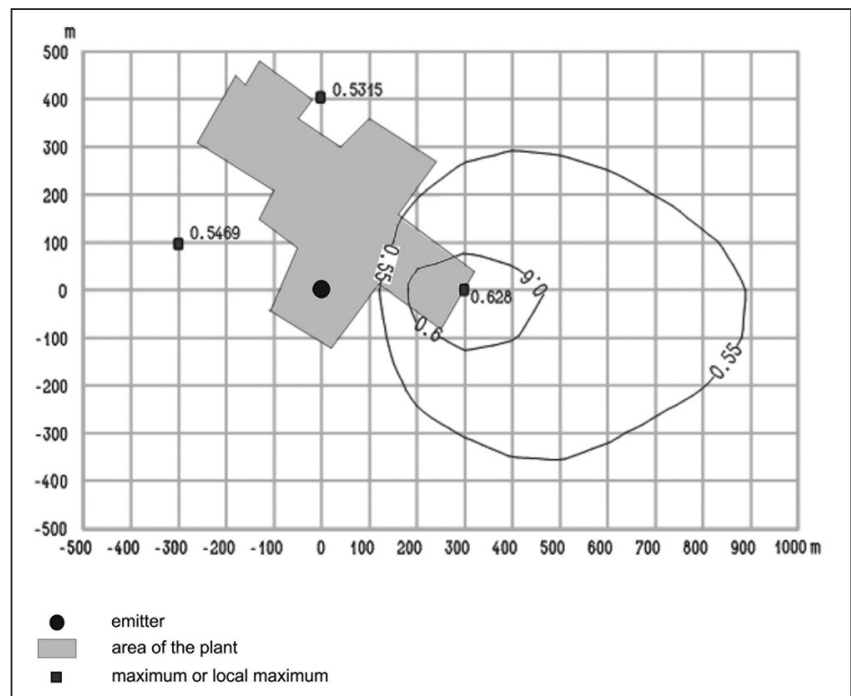

Fig. 2. Model - estimated mean annual concentration of hydrogen sulphide in the immediate vicinity of the emitter.

\section{DISCUSSION}

In normal conditions, hydrogen sulphide is a gas characterized by a repulsive odour of rotten eggs. The central nervous system and the lungs are the major target organs in acute poisoning with hydrogen sulphide. Common complications include bronchopneumonia and pulmonary oedema (5-11).

Low concentrations result in painful inflammation of the conjunctiva and corneal erosion, irritated nose and throat, and bronchitis. A number of neurological and neuropsychological changes following the acute toxicity have been recorded (2). Some epidemiologic studies have reported compromised cognitive and sensory performance among individuals exposed to low concentrations of hydrogen sulphide. In separate exposure sessions administered in random order during three consecutive weeks, 74 healthy subjects were exposed to $70 \mu \mathrm{g} / \mathrm{m}^{3}(0.05 \mathrm{ppm}), 700 \mu \mathrm{g} / \mathrm{m}^{3}$ $(0.5 \mathrm{ppm})$ and $7,000 \mu \mathrm{g} / \mathrm{m}^{3}(5 \mathrm{ppm}) \mathrm{H}_{2} \mathrm{~S}$. During each exposure session, subjects completed ratings and tests before $\mathrm{H}_{2} \mathrm{~S}$ exposure (baseline) and during the final hour of the 2-hour period. Increases in ratings of odour intensity, irritation and unpleasantness were observed. Total severity of the symptoms was not significantly elevated across any exposure condition, but anxiety symptoms were significantly higher in the $7,000 \mu \mathrm{g} / \mathrm{m}^{3}$ than in the $70 \mu \mathrm{g} / \mathrm{m}^{3}$ condition. Increased anxiety was significantly related to ratings of irritation due to odour. Analyses revealed significantly increased ratings of intensity at 80 and $90 \mathrm{~min}$ for pairwise comparison of all exposure conditions and for pairwise comparison at $100 \mathrm{~min}$ of $0.05 \mathrm{ppm}$ to $0.5 \mathrm{ppm}$, and of $0.05 \mathrm{ppm}$ to $5 \mathrm{ppm}$. This study confirmed that at environmental concentration $70 \mu \mathrm{g} / \mathrm{m}^{3}$, subjects rate the odour as more intense than baseline air (13).

It is believed that hydrogen sulphide at a concentration of 6.6 $\mu \mathrm{g} / \mathrm{m}^{3}$ is sensed by $50 \%$ of subjects as the smell of rotten eggs (14). The concentration of $0.7 \mu \mathrm{g} / \mathrm{m}^{3}$ is considered "odour threshold low", $14 \mu \mathrm{g} / \mathrm{m}^{3}$ "odour threshold high" (15), while $11 \mu \mathrm{g} / \mathrm{m}^{3}$ is the geometric mean value from 26 source data (16).

Relative to control communities, Legator et al. (17) reported higher odds ratios for 9 of 12 symptom categories with the highest odds ratios for central nervous, respiratory and blood systems (e.g. clotting disorder, bruising, anaemia) among residents living in communities in Texas and Hawaii, where maximum 2-hour $\mathrm{H}_{2} \mathrm{~S}$ concentration of $140-280 \mu \mathrm{g} / \mathrm{m}^{3}$ and $280-700 \mu \mathrm{g} / \mathrm{m}^{3}$, respectively, were documented. A study of residents from Rotorua, New Zealand, where $\mathrm{H}_{2} \mathrm{~S}$ exposure associated with geothermal energy was documented in the community, reported increased incidence of nervous system and sense organ diseases $(18,19)$.

Jaakkola et al. (20) reported that exposure to hydrogen sulphide in people living in the area with the pulp-mill caused 12 times more eye irritation compared to people not exposed to hydrogen sulphide. These effects were observed at the mean annual hydrogen sulphide concentration of $6 \mu \mathrm{g} / \mathrm{m}^{3}$. However, the reported ocular symptoms may have been caused by the exposure to peak concentrations of hydrogen sulphide (daily peaks as high as 100 $\mu \mathrm{g} / \mathrm{m}^{3}$ ) or co-exposure to methyl mercaptan and methyl sulphides.

Series of studies reported the results of the South Karelia Air Pollution Study which, in the year 1986, began to evaluate the effects of a low-level mixture of air pollutants on human health from the pulp mills in South Karelia and elsewhere in Finland (21). These studies have demonstrated that low levels of hydrogen sulphide in combination with other sulphur-containing pollutants 
and, possibly, in combination with particulates and/or sulphur dioxide can have an adverse effect on respiratory health. However, at present they are not able to tell whether this means the low annual average total reduced sulphur (TRS) levels at $1.2 \mu \mathrm{g}$ / $\mathrm{m}^{3}$ or the daily average concentrations $56 \mu \mathrm{g} / \mathrm{m}^{3}$, which are associated with these findings. The levels measured in Ružomberok neighbourhood foreshadow quite similar results (22).

According to WHO health risk depends on short-term concentrations of hydrogen sulfide. WHO establishes ambient air quality level for $\mathrm{H}_{2} \mathrm{~S}$ of $150 \mu \mathrm{g} / \mathrm{m}^{3}$ during 24 hours averaging period. It is derived from the lowest adverse effect level of hydrogen sulphide of $15 \mathrm{mg} / \mathrm{m}^{3}$, when eye irritation is caused, taking into account a relatively high protection factor of 100 (23).

Application of the Provisional Advisory Levels (PALs) protocols was performed for hydrogen sulphide as experimental data permitted. PALs are a tiered set of exposure values used to inform risk-based decision making during a response to environmental contamination involving hazardous chemicals. There are advisory levels for exposure to chemicals of the general public (including susceptible and sensitive sub-populations), developed for the following exposures to contaminated air and water. Three levels distinguished by severity of toxic effects are developed for inhalation exposures for the general public: PAL 1 (mild, transient, reversible effect), PAL 2 (serious, possibly irreversible effect), and PAL 3 (severe effect or lethality). $\mathrm{H}_{2} \mathrm{~S}$ inhalation PAL values for 24-hour exposure are PAL $1=1.2 \mathrm{ppm}\left(1.7 \mu \mathrm{g} / \mathrm{m}^{3}\right)$; PAL $2=7 \mathrm{ppm}\left(9.7 \mu \mathrm{g} / \mathrm{m}^{3}\right)$; and PAL $3=27 \mathrm{ppm}\left(37.6 \mu \mathrm{g} / \mathrm{m}^{3}\right)$; 30-day and 90-day inhalation exposure values are PAL $1=0.85$ $\operatorname{ppm}\left(1.2 \mu \mathrm{g} / \mathrm{m}^{3}\right)$ and PAL $2=3 \mathrm{ppm}\left(4.2 \mu \mathrm{g} / \mathrm{m}^{3}\right)$. PAL 3 values for 30-day and 90-day exposures are not recommended due to insufficient data. Long-term data were insufficient to estimate 2-year inhalation (24).

At selected immission measuring points (in villages Jerzmanowa, Bukwica, Przesieczna, and Jaczow) in any of the 1-hour air samples, hydrogen sulphide was not detected at concentrations exceeding $20 \mu \mathrm{g} / \mathrm{m}^{3}$ and in any of the 5-hour air samples hydrogen sulphide was not detected at concentrations exceeding $4 \mu \mathrm{g} / \mathrm{m}^{3}$. Using ZANAT ${ }^{\circledR}$ the estimated maximum 1-hour concentration of hydrogen sulphide was below $1 \mu \mathrm{g} / \mathrm{m}^{3}$. It seems reasonable to assume that concentrations of hydrogen sulphide in atmospheric air, those estimated from the determinations of the emission as well as those detected during the measurement days in the air of the selected sites do not result in hazards to the health of the residents. Due to its foul smell, hydrogen sulphide may be regarded as a slight annoyance to the inhabitants of the studied area. The Gaussian Dispersion Modelling has shown that maximum 1-hour concentration $0.7 \mu \mathrm{g} / \mathrm{m}^{3}$ - probably the lowest hydrogen sulphide odour threshold described in the literature - covers the area of all selected villages.

Attempts to regulate the problem of the population protection against the growing odour nuisance from business operations have been undertaken in many countries. The perception of odours is subjective, and that is why assessment of odour nuisance is difficult. The boundary between the acceptable and unacceptable nuisance is made vague by many factors, such as differences in the sensitivity of individual people to odour, the character of the landscape, economic situation in the region, etc., making it difficult to arrive at satisfactory solutions. The Odour Law has not been yet enacted in Poland or EU countries - standards for noxious odours have not been set, which is one of the reasons for the rapid increase in the number of complaints addressed, among others, to the Inspectorates for Environmental Protection. Effective legislative action should be undertaken to protect citizens from such noxious factors as odours.

In view of the study purpose mainly the short term ( 24 hours) data are adequate for health risk assessment. On the other hand in 2000, the U.S. Environmental Protection Agency (EPA) (25) has estimated inhalation reference concentrations (RfC) for hydrogen sulphide at $2 \mu \mathrm{g} / \mathrm{m}^{3}$ based on the research of Brenneman et al. (26) in rats. Rhinitis was adopted as the critical effect. RfC value is the estimate of the concentration of toxic substance in the air (with a range of uncertainty as high as one order of magnitude), which probably will not result in perceptible risk of harmful effects in the entire human population (including sensitive subgroups), exposed daily by inhalation throughout the whole life span. Uncertainty factor is a parameter used to determine the presumably safe environmental exposure limits for humans. Estimated by ZANAT ${ }^{\circledR}$ mean annual concentration in selected villages is less than 0,55 $\mu \mathrm{g} / \mathrm{m}^{3}$, so it is about four times lower that RfC.

\section{CONCLUSIONS}

In summary, the estimated and the determined immission concentrations of hydrogen sulphide in 4 villages located in the vicinity of the copper mine exhaust shaft were many times lower than the relevant existing reference benchmarks defined as acceptable levels of substances in the air plus the margin of tolerance or specified for the protection of human health and for the protection of plants. They do not pose any risk to the health of people living in the area.

As indicated by the available data on the threshold odour of hydrogen sulphide, the estimated concentrations of hydrogen sulphide may be sensed by humans. It would not be reasonable to exclude that in some periods of time an extremely sensitive person may sense odour of hydrogen sulphide in selected village at a short distance from the emitter of the mine extracting copper ore, i.e. 2 to $5 \mathrm{~km}$.

In the next step it would be useful to investigate expected distribution of short term concentrations during the year depending on seasonal influence.

\section{Funding}

This work was funded by the KGHM Polska Miedź S.A., Lubin in 2012 under the contract "Risk assessment of potential health effects related to the emission and immission of chemicals emitted from the exhaust shafts mine KGHM Polska Miedź S.A.”

\section{REFERENCES}

1. Simonton DS, King S. Hydrogen sulfide formation and potential health consequences in coal mining regions. Water Qual Expo Health. 2013;5(2):85-92.

2. Križan V, Kemka R, Hluchán̆ E. Determination of hydrogen sulfide calorimetric method in air analysis. In: Križan V, Kemka R, Hlucháň E, editors. Air analysis. Bratislava: ALFA; 1981.p. 322-325. (In Slovakian.)

3. Janoszka K, Wziątek A, Gromiec JP. Evaluation of methods for monitoring air concentrations of hydrogen sulfide. Med Pr. 2013;64(3):449-54. (In Polish.) 
4. Reference values for certain substances in the air Ordinance of Minister of Environment of 2010. J. of Law. 2010 Jan 2;(16):item 87. (In Polish.)

5. ACGIH American Conference of Governmental Industrial Hygienists Inc. Documentation of the threshold limit values and biological exposure indices. Hydrogen sulphide. Cincinnati: ACGIH; 2012.

6. Hessel PA, Herbert FA, Melenka LS, Yoshida K, Nakaza M. Lung health in relation to hydrogen sulfide exposure in oil and gas workers in Alberta, Canada. Am J Ind Med. 1997 May;31(5):554-7.

7. Mehlman MA. Dangerous and cancer-causing properties of products and chemicals in the oil refining and petrochemical industry. Part VII: Adverse health effects and toxic manifestations caused by exposure to hydrogen sulfide, a component of crude oil. In: Mehlman MA, Upton A, editors. The identification and control of environmental and occupational diseases: Hazards and risks of chemicals in the oil refining industry, advances in modern environmental toxicology. Princeton: Princeton Scientific Publishing; 1994. p. 321-340.

8. Schneider JS, Tobe EH, Mozley PD Jr., Barniskis L, Lidsky TI. Persistent cognitive and motor deficits following acute hydrogen sulphide poisoning. Occup Med (Lond). 1998 May;48(4):255-60.

9. Tvedt B, Skyberg K, Aaserud O, Hobbesland A, Mathiesen T. Brain damage caused by hydrogen sulfide: a follow-up study of six patients. Am J Ind Med. 1991;20(1):91-101.

10. Wasch HH, Estrin WJ, Yip P, Bowler R. Cone, JE. Prolongation of the P-300 latency associated with hydrogen sulfide exposure. Arch Neurol. 1989 Aug;46(8):902-4.

11. Kilburn KH. Case report: profound neurobehavioral deficits in an oil field worker overcome by hydrogen sulfide. Am J Med Sci. 1993 Nov;306(5):301-5.

12. Stetkiewicz J. Hydrogen sulfide. Documentation of occupational exposure limits. Podst Met Oceny Środ Pr. 2011;4(70):97-118. (In Polish.).

13. Fiedler N, Kipen H, Ohman-Strickland P, Zhang J, Weisel C, Laumbach R, et al. Sensory and Cognitive Effects of Acute Exposure to Hydrogen Sulfide. Environ Health Perspect. 2008 Jan;116(1):78-85.

14. Powers W, Corzanego M. The science of smell. Part 1: Odor perception and physiological response [Internet]. Ames: Iowa State University; 2004 [cited 2015 Apr 20]. Available from: http://www.extension.iastate.edu/ Publications/PM1963A.pdf.

15. Ruth JH. Odor thresholds and irritation levels of several chemical substances: A review. Am Ind Hyg Assoc J. 1986 Mar;47(3):A142-51.

16. Amoore JE, Hautala E. Odor as an aid to chemical safety: odor thresholds compared with threshold limit values and volatilities for 214 industrial chemicals in air and water dilution. J Appl Toxicol. 1983 Dec;3(6):27290
17. Legator MS, Singleton CR, Morris DL, Philips DL. Health effects from chronic low-level exposure to hydrogen sulfide. Arch Environ Health. 2001 Mar-Apr;56(2):123-31.

18. Bates MN, Garret N, Graham B, Read D. Air pollution and mortality in the Rotorua geothermal area. Aust N Z J Public Health. 1997 Oct;21(6):58186.

19. Bates MN, Garret N, Shoemack P. Investigation of health effects of hydrogen sulfide from a geothermal source. Arch Environ Health. 2002 Sep-Oct;57(5):405-11.

20. Jaakkola JJ, Vilkka V, Marttila O, Jäppinen P, Haahtela T. The South Karelia Air Pollution Study. The effects of malodorous sulfur compounds from pulp mills on respiratory and other symptoms. Am Rev Respir Dis. 1990 Dec;142(6 Pt 1):1344-50.

21. Jaakkola JJ, Partti-Pellinen K, Marttila O, Miettinen P, Vilkka V, Haahtela T. The South Karelia Air Pollution Study: changes in respiratory health in relation to emission reduction to malodorous sulfur compounds from pulp mills. Arch Environ Health. 1999 Jul-Aug;54(4):254-63.

22. Drimal M, Koppová K, Klöslová Z, Fabiánová E. Environmental exposure to hydrogen sulfide in central Slovakia (Ružomberok area) in context of health risk assessment. Centr Eur J Public Health. 2010 Dec;18(4):224-9.

23. World Health Organization. Air quality guidelines for Europe. 2nd ed. European series No. 91. Copenhagen: WHO Regional Office for Europe 2000.

24. Marshall T, Dorman D, Gardner D, Adeshina F. Provisional Advisory Levels (PALs) for hydrogen sulfide (H2S). Inhal Toxicol. 2009 Dec;21 Suppl 3:56-72.

25. U.S. Environmental Protection Agency. Toxicological review of hydrogen sulfide (CAS No. 7783-06-4) in support of summary information on the Integrated Risk Information System (IRIS). EPA/635/R-03/005 [Internet]. Washington, D.C.: U.S. Environmental Protection Agency; 2003 [cited 2015 Apr 20]. Available from: http://www.epa.gov/iris/toxreviews/0061tr pdf.

26. Brenneman KA, James RA, Gross EA, Dorman DC. Olfactory neuron loss in adult male $\mathrm{CD}$ rats following subchronic inhalation exposure to hydrogen sulfide. Toxicol Pathol. 2000 Mar-Apr;28(2):326-33.

Received April 3, 2014 Accepted in revised form April 21, 2015 